\title{
SYNTHESIS OF SOME NEW PHTHALIZINE DIONE DERIVATIVES WITH THEIR ANTI- MICROBIAL AND ANTI-CANCER ACTIVITY
}

\author{
Samir M. El Rayes ${ }^{1}$, Ibrahim A. I. Ali ${ }^{1}$, Wessam IBRAHIM ${ }^{1}$ \\ ${ }^{1}$ Department of Chemistry, Faculty of Science, Suez Canal University, Ismailia, Egypt
}

\begin{abstract}
Starting from methyl-1,4-Dioxo-3-phenyl-3,4-dihydro-1H-phthalazin-2-yl-acetate (2) eighteen newly Phthalazine dione derivatives were synthesized. The starting material 2 was prepared by $\mathrm{N}$-alkylation of 2-phenyl-2,3-dihydrophthalazine-1,4-dione (1) with ethyl chloro acetate under reflux over night. 2-(1,4-dioxo-3-phenyl-3,4dihydrophthalazin-2(1H)-yl)acetohydrazide (3) was prepared by hydrazinolysis of ester 2 with hydrazine hydrate under reflux. Monopeptide methyl-3-[2-(1,4-dioxo-3phenyl-3,4-dihydro-1H-phthalazin-2-yl)-acetylamino]-alkanoate 4a-c were prepared via azide coupling method by coupling of hydrazide 3 with different methyl ester of glycine, $\beta$-alanine and L-leucine respectively. The hydrazides 2-(1,4-Dioxo-3-phenyl3,4-dihydro-1H-phthalazin-2-yl)-N-(2-hydrazinocarbonyl-ethyl)-amides 5a-c were prepared by hydrazinolysis of esters 4a-c with hydrazine hydrate respectively. Similarly; dipeptides methyl-3-[2-(1,4-Dioxo-3-phenyl-3,4-dihydro-1H-phthalazin-2yl)-acetylamino]-propionylamino-alkanoates 6a-i were prepared form coupling of methyl esters of glycine, $\beta$-alanine and L-leucine with hydrazides 5a-c via azide coupling method. Schiff's base hydrazones N-[2-(Arylidene-hydrazinocarbonyl)ethyl]-2-(1,4-dioxo-3-phenyl-3,4-dihydro-1H-phthalazin-2-yl)-amides 7a-i were prepared by condensation of hydrazides 5a-c with different aldehydes such as 4chlorobenzaldehyde, 4-methoxybenzaldehyde and 4-nitrobenzaldehyde.
\end{abstract}

The anti-bacterial activities of the synthesized compound were screened in vitro against E.coli, Salmonella and Staphylococcus aureus with comparison to 2-phenyl2,3-dihydrophthalazine-1,4-dione (1). The results showed that most compounds have activities against E.coli and a little compounds were sensitive to Salmonella but there 
no significance response to Staphylococcus aureus. Also the anti-cancer activities were assayed and some synthesized phthalazinedione has high activity in inhibition of HEPG2 and MCF-7 cancer cell lines.

Keywords: Chemoselective, phthalazinone, azide coupling, monopeptide and dipeptide, Schiff s s basses, anticancer, anti-microbial

\section{INTRODUCTION}

Recently, Our research group focused their efforts on searching for new anticancer drugs $^{1,2}$ where the anticancer drugs research is never ending to obtain lower toxicity and more selectivity products towards tumor cells.

Phthalazine dione and its derivatives have attracted much attention to chemists and pharmacologists because of their broad spectrum biological activities and applications where it possessing versatile chemical, industrial and biological properties such as antitumor ${ }^{3}$, cytotoxic ${ }^{4}$, anticonvulsant, cardiotonic, vasorelaxant, antimicrobial and anti-inflammatory properties ${ }^{5}$

It was reported that many Phthalazine nucleus has emerged as a promising and attractive one in the development of novel anticancer agents ${ }^{6-9}$

such as 5 amino-2,3-dihydro-1,4-phthalazinedione A figure 1 has therapeutic use to identification of poly(ADP-ribose) polymerase, an enzyme that responds to DNA damage and to application in treating skin aging, Alzheimer's, atherosclerosis, osteoarthritis, osteoporosis, age-related macular degeneration, muscular dystrophy, immune senescence, viral infections and cancer as diseases involving the function of poly (ADP-ribose) polymerase. Also 3-Amino-2-chloro-1-[3-(5-methyl-1-phenyl-1H[1,2,3]triazol-4-yl(-1-phenyl-1H-pyrazol-4-yl]-7-nitro-1H-pyrazolo[1,2-b]phthalazine -5,10-dione $\mathbf{B}$ figure 1 has antiproliferative efficacy on human hepatic cancer cell lines. More over 6-Amino-1-methyl-3-phenylamino-2,3-dihydro-1H-pyrazolo[1,2b]phthalazine-5,10-dione $\mathbf{C}$ figure 1 which used as anti-hypoxic and antipyretic 
agent. 4-[3-(4-Cyclopropanecarbonyl-piperazine-1-carbonyl)-4-fluoro-benzyl]-3,4dihydro-2H-phthalazin-1-one. Olaparib (Lynparza ${ }^{\circledR}$ ) D figure 1 is an oral small molecule phthalazine based poly ADP-ribose polymerase (PARP) inhibitor being developed for the treatment of solid tumors.<smiles>Nc1cccc2c(=O)[nH][nH]c(=O)c12</smiles>

A<smiles></smiles>

C<smiles>Cc1c(-c2nn(-c3ccccc3)cc2C2C(Cl)=C(N)n3c(=O)c4cc([N+](=O)[O-])ccc4c(=O)n32)nnn1-c1ccccc1</smiles>

B<smiles>CC(=O)c1cc(CC2NNC(=O)c3ccccc32)ccc1F</smiles>

$\mathrm{D}$<smiles>O=C(C1CC1)N1CCNCC1</smiles>

Figure 1 Some common phthalizine compounds used as anti cancer drugs

Therefore, many methods have been reported for synthesis of phthalazine derivatives ${ }^{10}$. A series of differently substituted 1,4-phthalazinedione derivatives were synthesized in good yield starting from phthalic anhydride or 4-chlorophthalic anhydride ${ }^{11}$.

\section{RESULTS \& DISCUSSION:}

Our research group reported early that ${ }^{12-15}$, how we can control on chemoselective alkylation in both amides and thioamides. As extension of this studies, we achieve N-Alkylation of 2-phenyl-2,3-dihydrophthalazine-1,4-dione

(1) with ethyl 
choloracetate in acetone which proceed selectively on $\mathrm{N}$ atom not at $\mathrm{O}$ atom or even in competition reaction at both atoms. We can explain that depending on their behavior towards electrophiles according to reaction control points as basisty and neucleophilicity of both $\mathrm{N}$ and $\mathrm{O}$ atoms. The product was methyl-1,4-Dioxo-3phenyl-3,4-dihydro-1H-phthalazin-2-yl-acetate (2) prove that the $\mathrm{N}$ atom in present system is stronger neucleophile more than Oxygen i.e this reaction new evidence for basis of chemoselective reactivity of heterocyclic amides towards electrophiles scheme1.

The ester $\mathbf{2}$ underwent hydrazinolysis under reflux with hydrazine hydrate to produce hydrazide 2-(1,4-dioxo-3-phenyl-3,4-dihydrophthalazin-2(1H)-yl)acetohydrazide (3) in excellent yield. Scheme 1

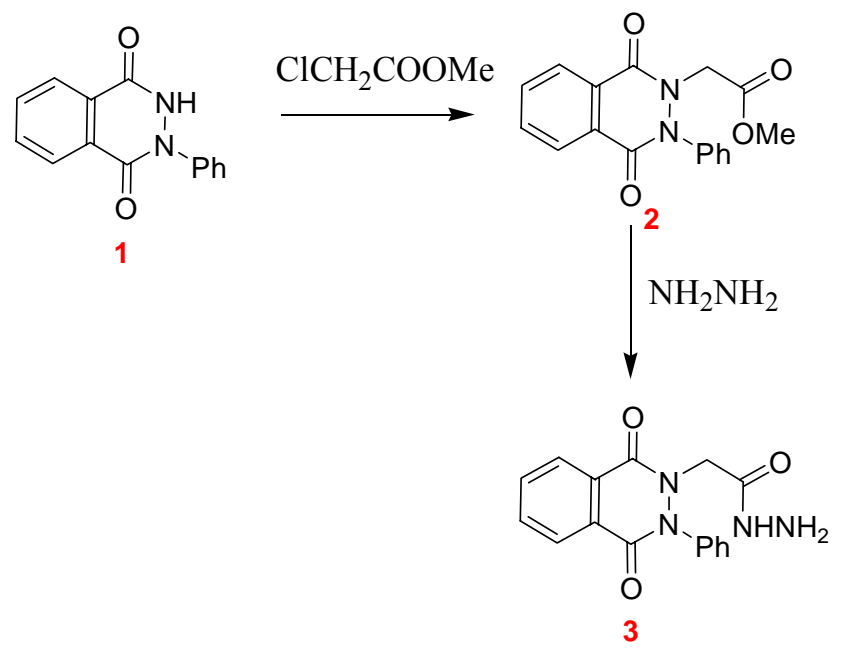

Scheme 1 Synthesis of ester $\mathbf{2}$ and corresponding hydrazide $\mathbf{3}$ from phthalizine dione

The charachterstic ${ }^{1} \mathrm{H}$ - NMR spectral peaks for hydrazide $3:{ }^{1} \mathrm{H}$ - NMR of compound $3{ }^{1} \mathrm{HNMR}$ (DMSO-d6): $\delta 4.32$ (s, 2H, NCH${ }_{2}$ ), 6.89-8.32 (m, 9H, Ar-H), 11.50 (s, 1H, $\mathrm{NH}, \mathrm{D}_{2} \mathrm{O}$ exchangeable), $\mathrm{NH}_{2}$ protons seemed to be exchanged by the solvent.

The hydrazide 3 coupled with amino acid methyl ester via azide coupling method which converted to the mono peptide methyl-3-[2-(1,4-dioxo-3-phenyl-3,4-dihydro1H-phthalazin-2-yl)-acetylamino]-alkanoate 4a-c. On hydrazinolysis of esters 4a-c with hydrazine hydrate corresponding hydrazides 5a-c were obtained in very good yield. Scheme 2 
General procedures for racemization-free azide coupling method ${ }^{16,17}$, for synthesis of compounds 4(a-c)

To cold solution $\left(0^{\circ} \mathrm{C}\right)$ of hydrazide $3(3.67 \mathrm{gm}, 0.01 \mathrm{~mol})$ in acetic acid $(15 \mathrm{ml}), 1 \mathrm{~N}$ $\mathrm{HCl}(15 \mathrm{ml})$ and water $(25 \mathrm{ml})$ was added a solution of $\mathrm{NaNO}_{2}(0.7 \mathrm{~g}, 0.01 \mathrm{~mol})$ in cold water $(15 \mathrm{ml})$. The reaction mixture was stirred at $\left(0^{\circ} \mathrm{C}\right)$ for 15 minute. The yellow syrup formed was extracted with cold Ethyl acetate $(30 \mathrm{ml})$, washed with cold $5 \% \mathrm{Na}_{2} \mathrm{CO}_{3}(30 \mathrm{ml})$ and finally dried over $\mathrm{Na}_{2} \mathrm{SO}_{4}$. To this solution amino acid ester $\mathrm{NH}_{2}(\mathrm{CHR}) \mathrm{COOMe} . \mathrm{HCl}(0.01 \mathrm{~mol})$ in ethyl acetate $20 \mathrm{ml}$ containing $2 \mathrm{ml}$ of $\mathrm{Et}_{3} \mathrm{~N}$ were added. The reaction mixture was kept at $\left(0^{\circ} \mathrm{C}\right)$ for $24 \mathrm{hrs}$ then at room temp for another $24 \mathrm{hrs}$. The solution was evaporated to dryness. The residue was crystallized from petroleum ether /ethyl acetate to give the desired product.
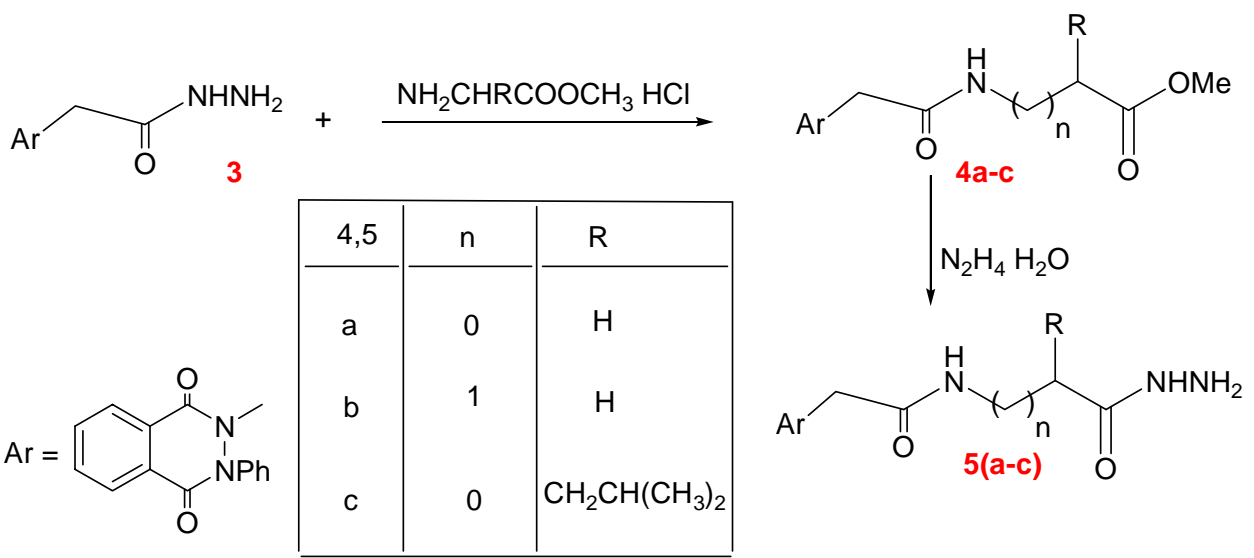

Scheme 2 Synthesis of monopeptides $\mathbf{4 a - c}$ and their corresponding hydrazides 5a-c

The chemical structure of the synthesized methyl 2-(2-(1,4-dioxo-3-phenyl-3,4dihydrophthalazin-2(1H)-yl)acetamido)acetate (4a) was confirmed by ${ }^{1} \mathrm{HNMR}$ which showed the following signals: a broad signal of $\mathrm{NHCH}_{2}$ at $6.91 \mathrm{ppm}$, duplet signal of $-\mathrm{NHCH}_{2}$ at $4.07 \mathrm{ppm}$ and singlet signal of $\mathrm{OCH}_{3}$ at $3.69 \mathrm{ppm}$

Similarly; The hydrazides 5a-c which could be re-coupled with another amino acids via azide coupling method to give di-peptied derivatives methyl-3-[2-(1,4-Dioxo-3- 
phenyl-3,4-dihydro-1H-phthalazin-2-yl)-acetylamino]-propionylamino-alkanoates 6a-i (Scheme 3).

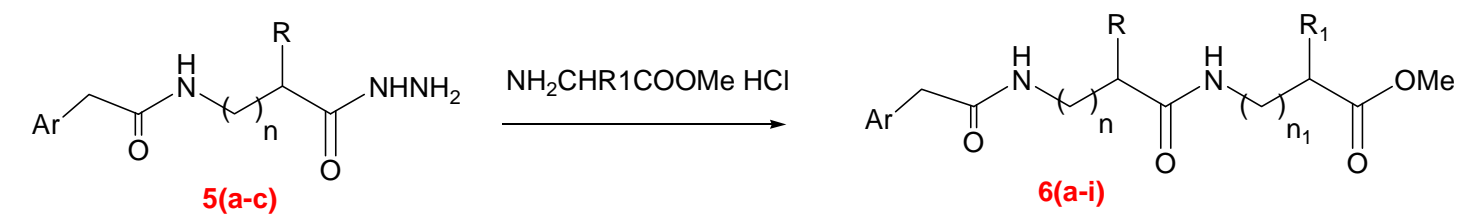

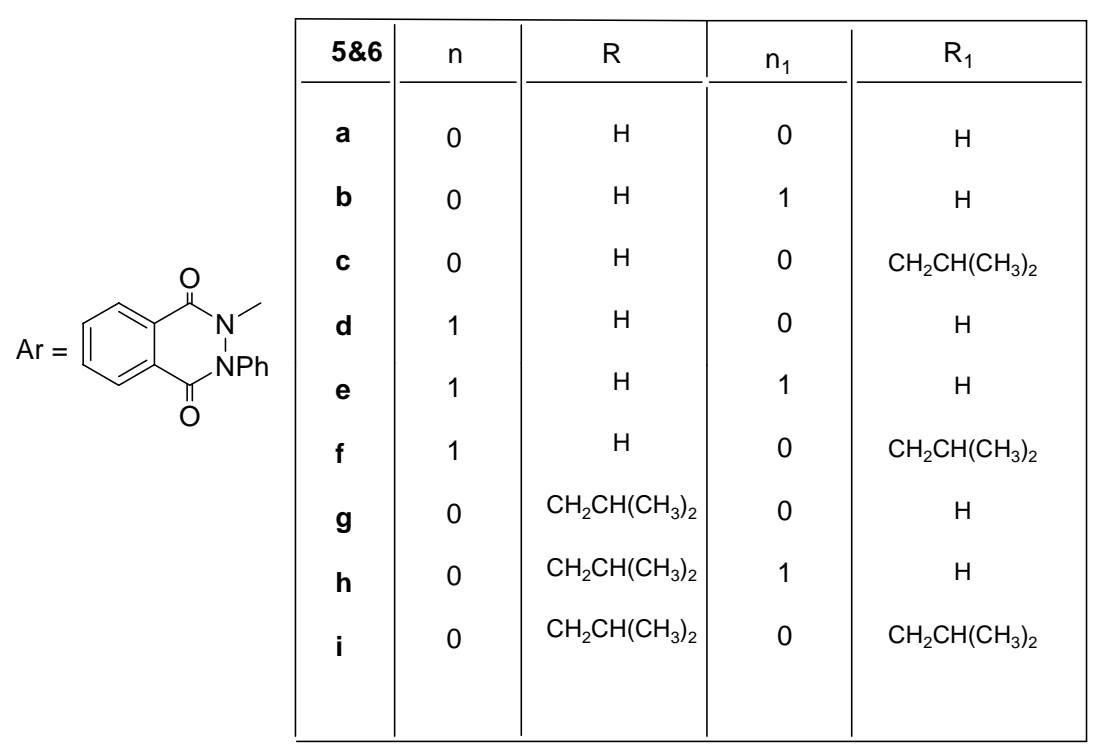

Scheme 3 Synthesis of dipeptides 6a-i from corresponding hydrazides 5a-c

The structure of 6a was elucidated via different analysis methods for example the ${ }^{1}$ HNMR of methyl 2-(2-(2-(1,4-dioxo-3-phenyl-3,4-dihydrophthalazin-2(1H)yl)acetamido)acetamido)acetate (6a) showed the following characteristic signals three singlet signal of three $\left(-\mathrm{CH}_{2}\right)$ at $4.83,4.00$ and $3.87 \mathrm{ppm}$ and singlet signal of $\mathrm{OCH}_{3}$ at $3.65 \mathrm{ppm}$.

More over the hydrazides 5a-c were condensed with carbonyl group of different aldehydes to give the corresponding Schiff ${ }^{\prime}$ s bases $7 \mathbf{7}-\mathbf{i}$.

General procedures ${ }^{18}$ for preparation of Schiff's base derivatives $7 \mathbf{7}-\mathbf{i}$

A mixture of hydrazides 5a-c $(0.01 \mathrm{~mol})$ and appropriate aromatic aldehydes $(0.01 \mathrm{~mol})$ was refluxed in ethanol $(25 \mathrm{ml})$ for $12 \mathrm{hrs}$, after cooling the collected solid crystallized from the proper solvent scheme 4. 


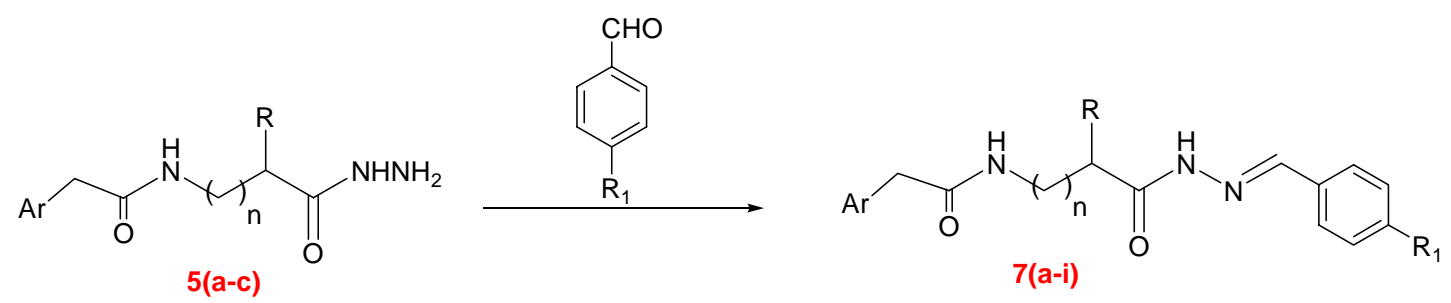

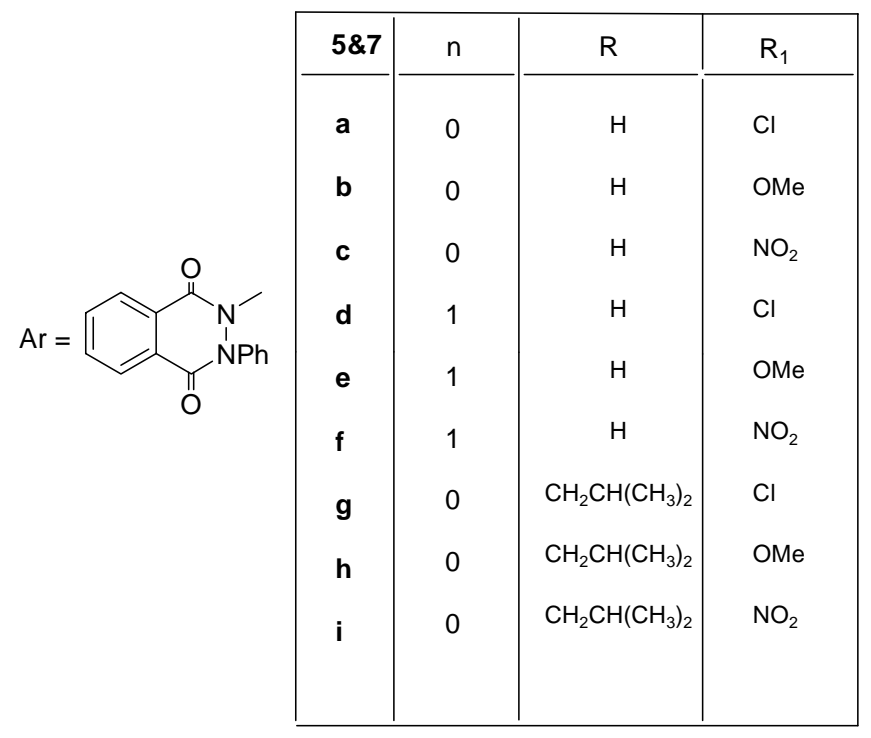

Scheme 4 Synthesis of Schiff"s bases 7a-i from corresponding hydrazides 5a-c

The structure of 7a was elucidated via different analysis methods for example the ${ }^{1}$ HNMR of N-[2-(4-Chloro-benzylidene-hydrazinocarbonyl)-ethyl]-2-(1,4-dioxo-3phenyl-3,4-dihydro-1H-phthalazin-2-yl)-acetamide 7a showed the following signals: a broad signal of $\mathrm{NH}$ at $11.47 \mathrm{ppm}$, multiplet signal of $4 \mathrm{H}$ of aromatic ring of Chlorobenzaldhyde at 7.37-7.52ppm and singlet signal of $\mathrm{CH}$ at $10.11 \mathrm{ppm}$.

Biological activity of the synthesized compounds.

\section{Molecular Docking Methodology:}

Bioinformatics including molecular modeling studies are very valuable at the present time in the field of drug discovery, saving money and effort needed for the screening of new compounds by guiding and confining the investigation to possible target/ targets. The use of docking simulation studies in our project is quite important to help in predicting the possible mode of action and structure activity relationship of the active derivatives and guiding the research future directions in compounds 
optimization and biochemical enzyme assay for the possible target enzymes. Key interactions at protein-protein interfaces constitute important targets for small molecule inhibition because of their specific arrangements and biological importance ${ }^{19}$.

All the molecular modeling studies were carried out on Intel ${ }^{\circledR}$ Core $^{\mathrm{TM}}$ i3 CPU, $2.40 \mathrm{GHZ}$ processor, and $3 \mathrm{~GB}$ memory with Windows 7 operating system using Molecular Operating Environment (MOE 2008-10 Chemical Computing Group, Canada) as the computational software ${ }^{20,21}$. Anti-bacterial activities of the synthesized benzotriazinone derivatives were investigated through correlation with E. coli Fab-H inhibitory activities, and the anti-cancer activity of compounds were screened through detection of their ability to act as Vitamin D receptor. The crystal structure of E. coli FabH-CoA complex structure (PDB code: 1HNJ), and the crystal structure of the nuclear receptor for vitamin D bound to its natural ligand (PDB code: 1DB1) were obtained from the freely accessible Protein data bank. The docking studies were performed after the verification process which was performed by redocking of the co crystallized ligand into the active site using the default settings. The synthesized derivatives were docked within the active site of the crystallized structures using the MOE dock tool in MOE, performed with the default values. Different conformers for each compound are imported by systematic conformational of the MOE and saved in an mdb data base file to be docked into the active site of the receptor. Each complex was analyzed for interaction, 2D and 3D images were taken by using MOE visualizing tool.

The results were evaluated based on binding affinity calculation together with cluster size determination and visually through possible interaction with key residues at the active site. 
Anti-cancer activity:

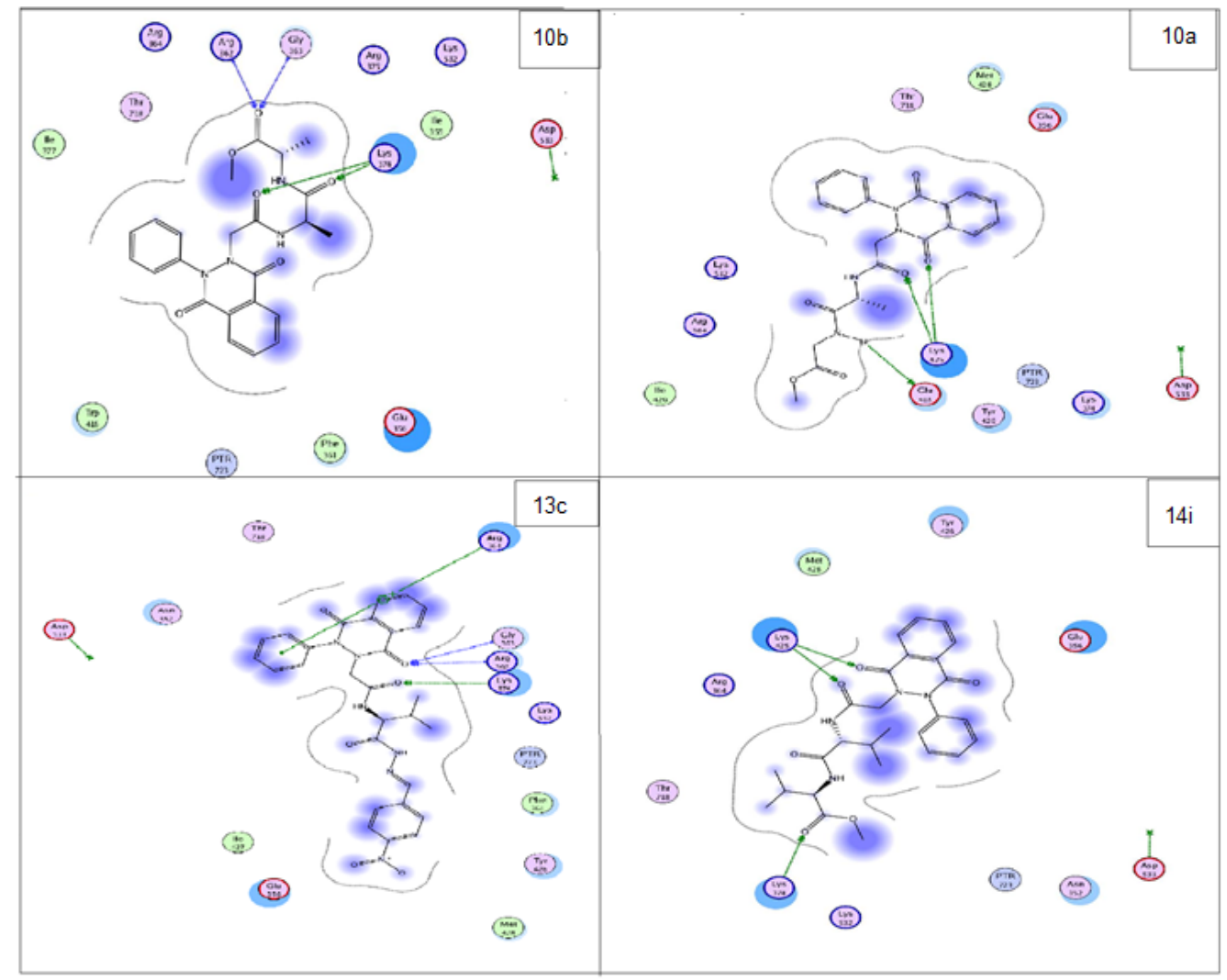




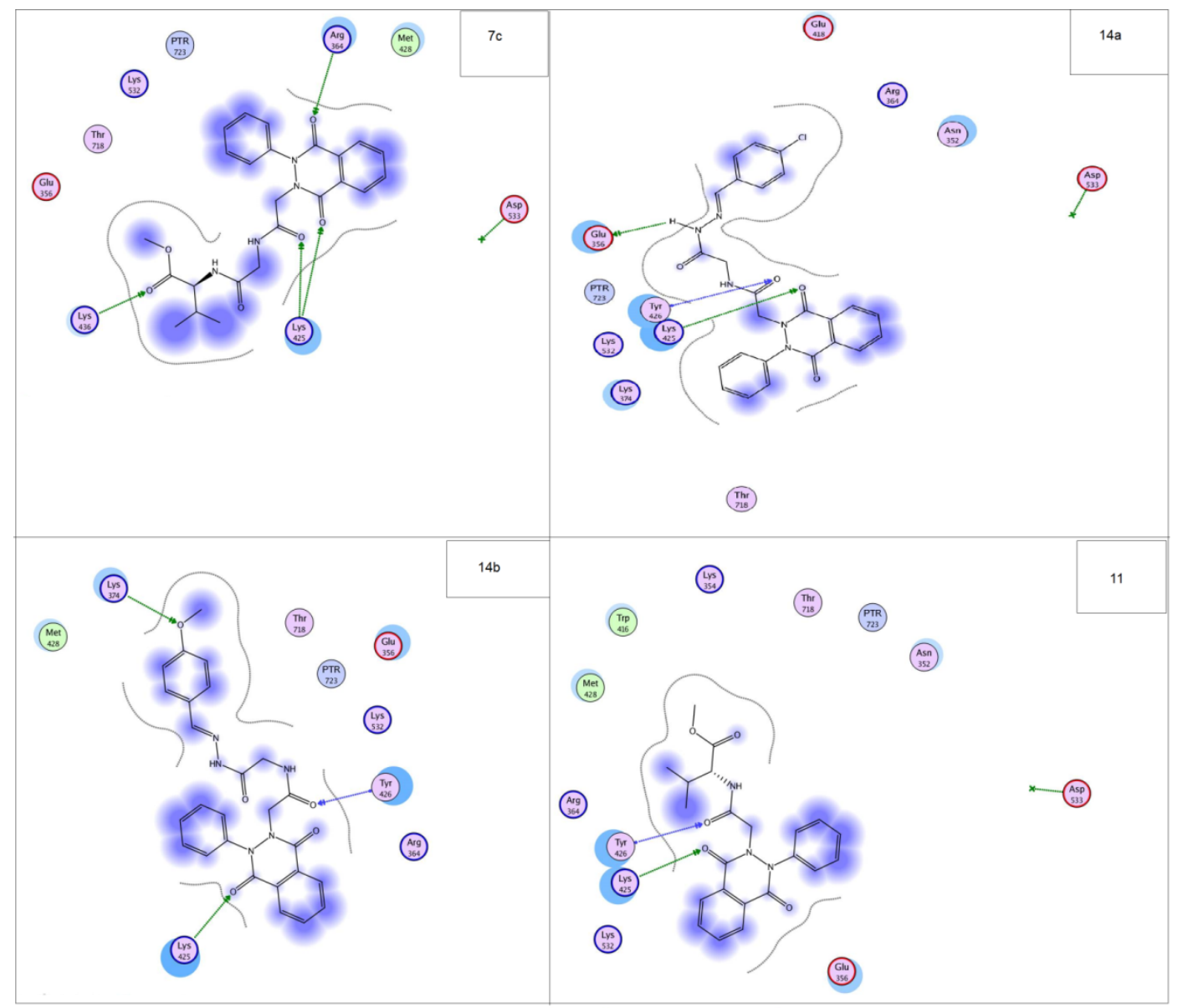




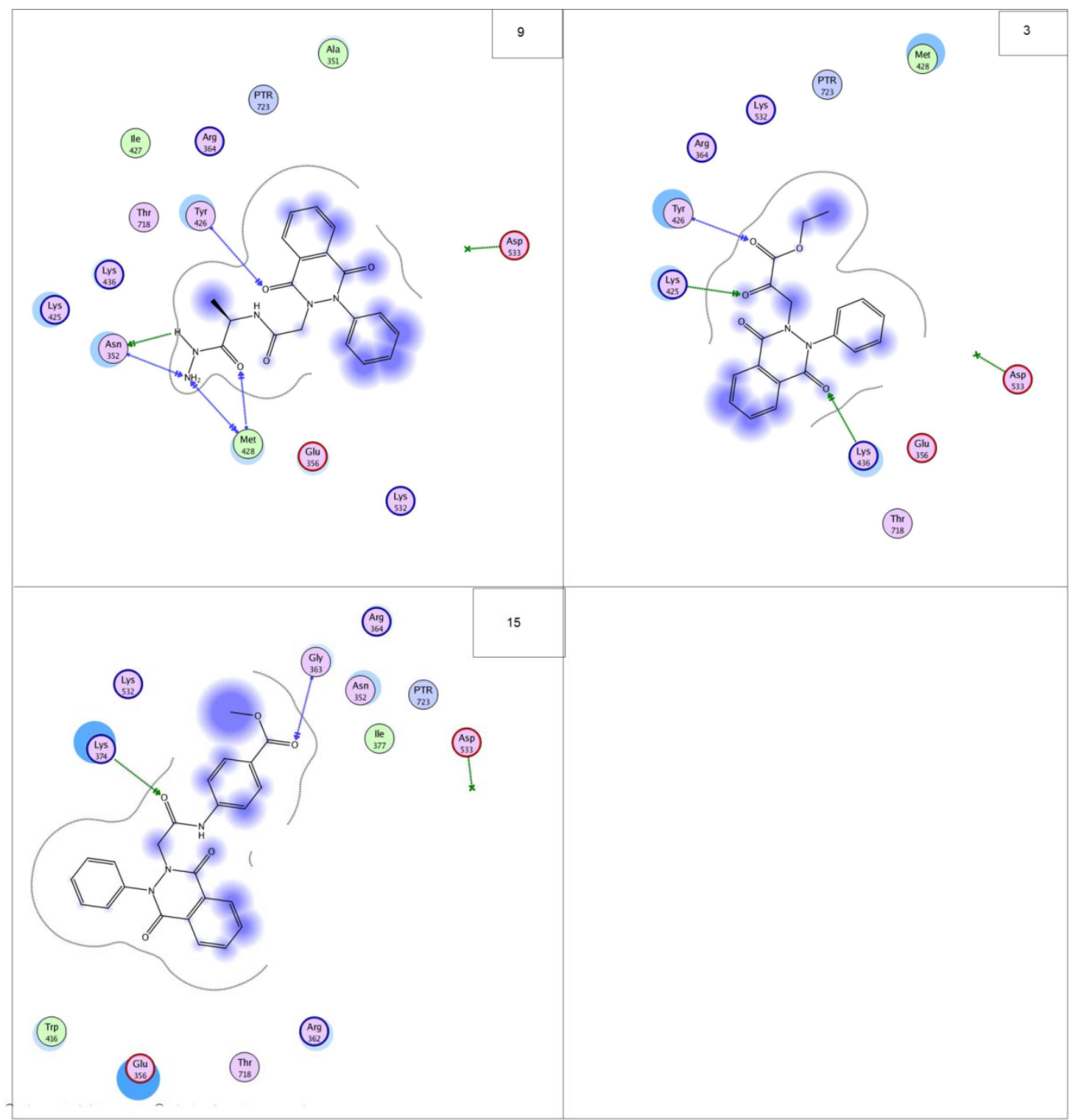


Anti-cancer activity (HEPG -2 \& MCF-7 Cell Lines)

Evaluation of cytotoxicity against HepG-2\& MCF-7 cell lines

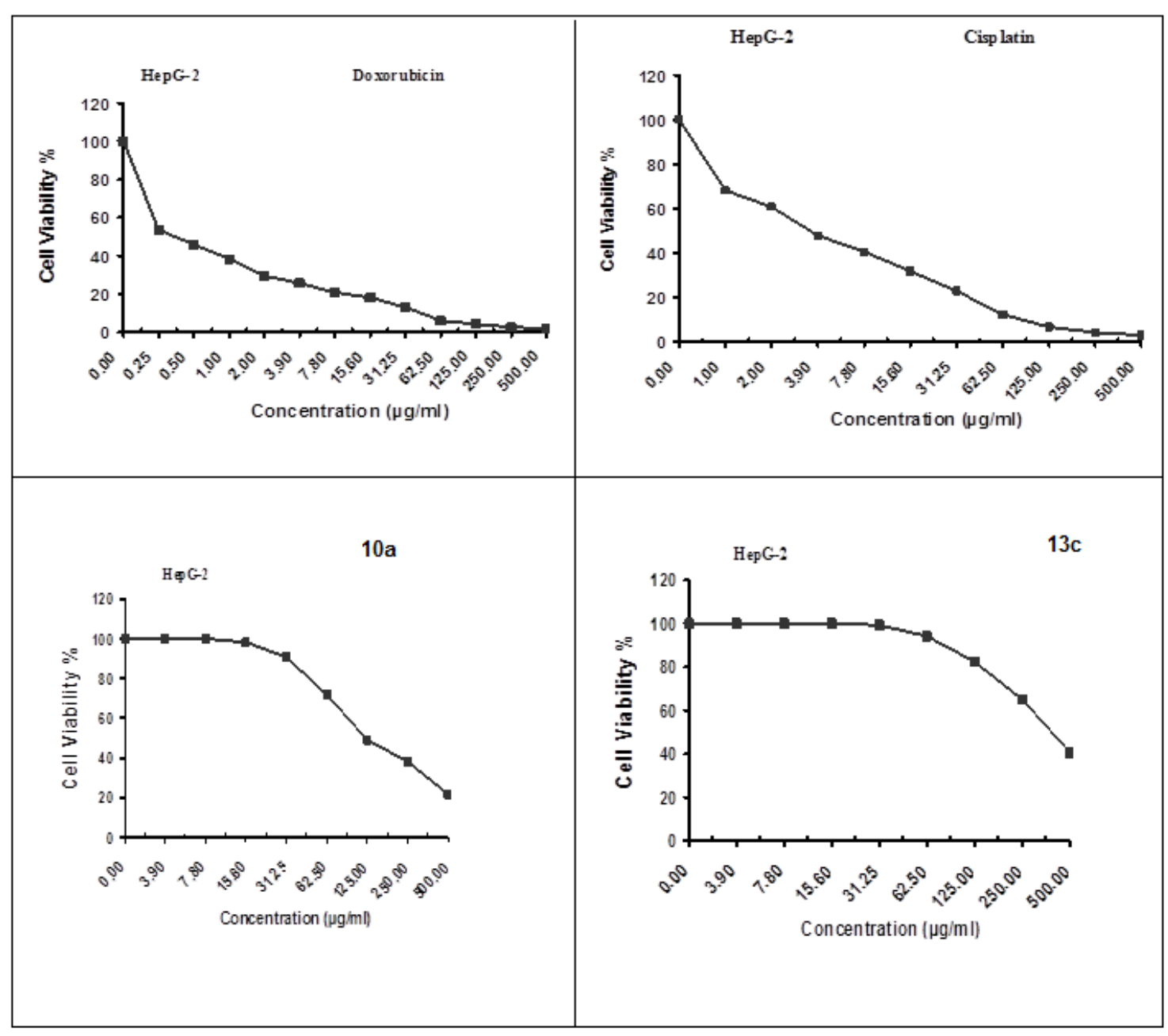




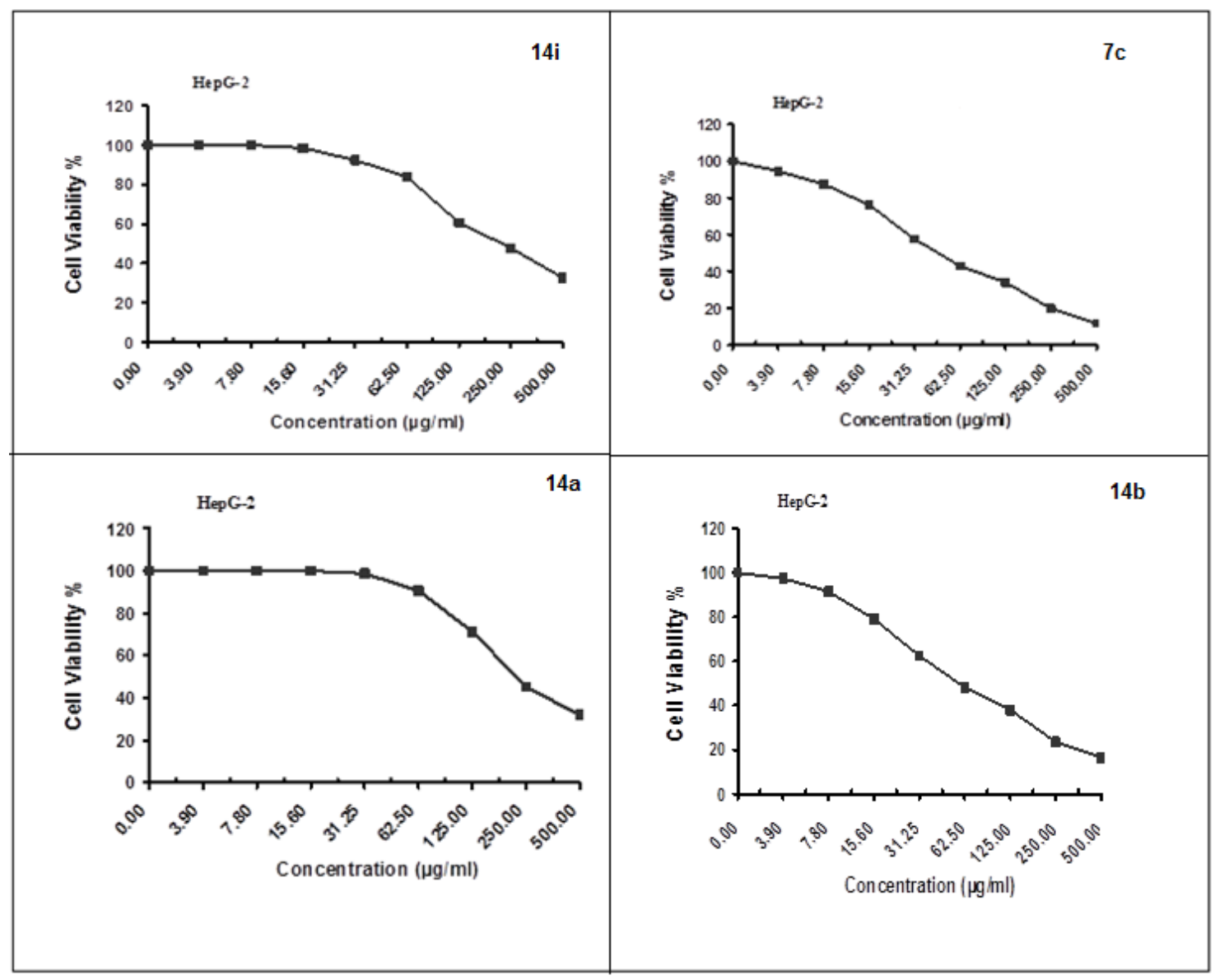




(1)




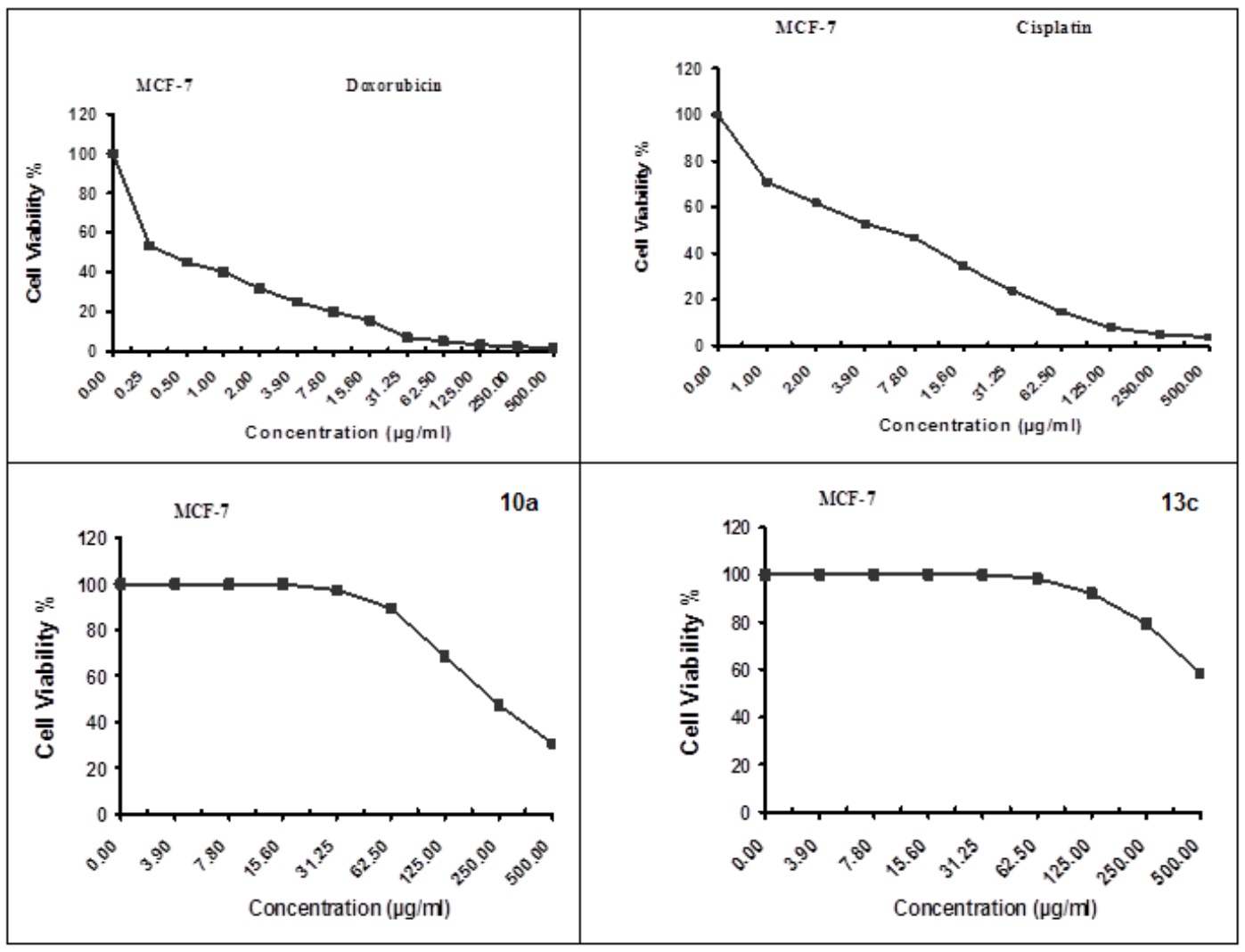




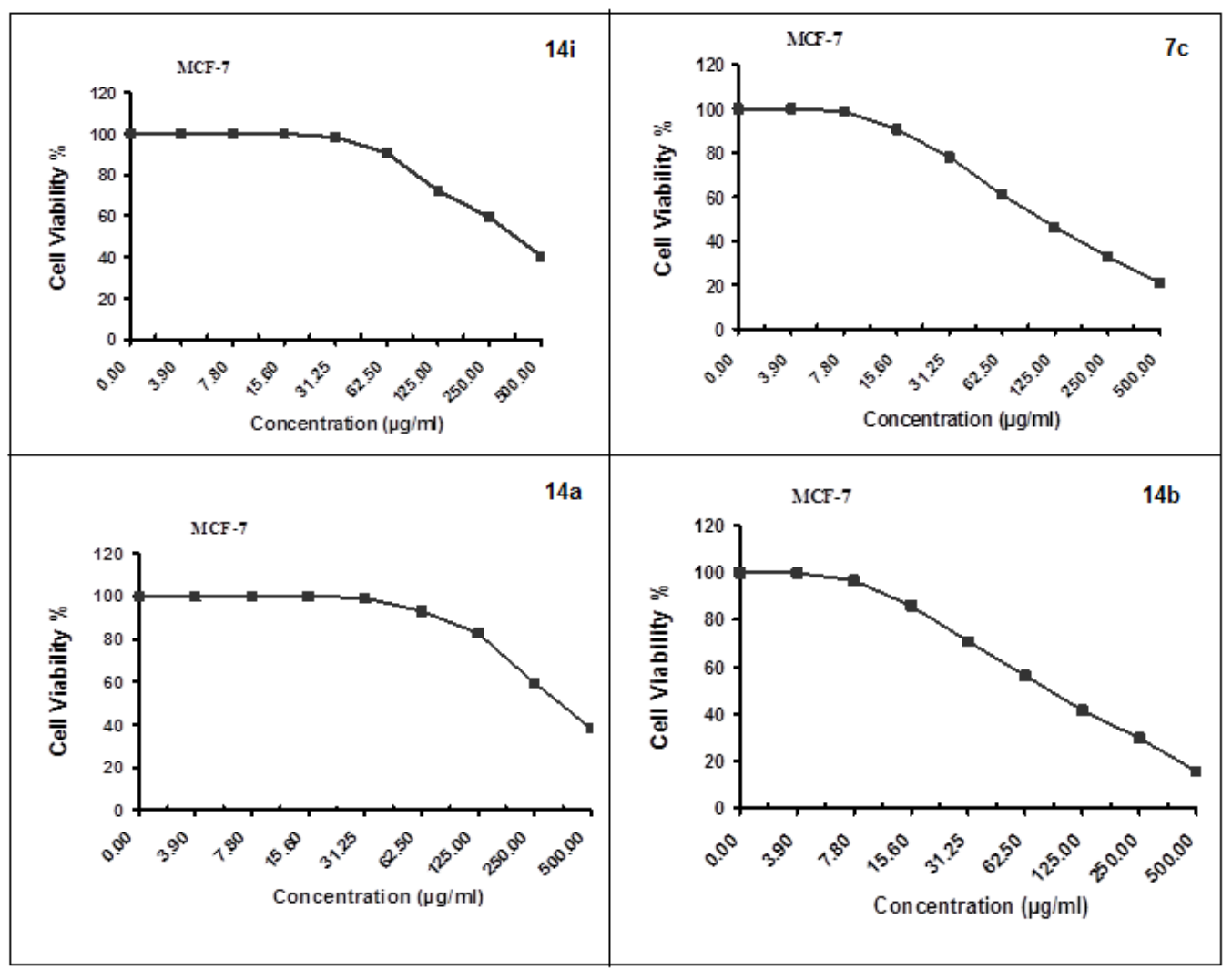




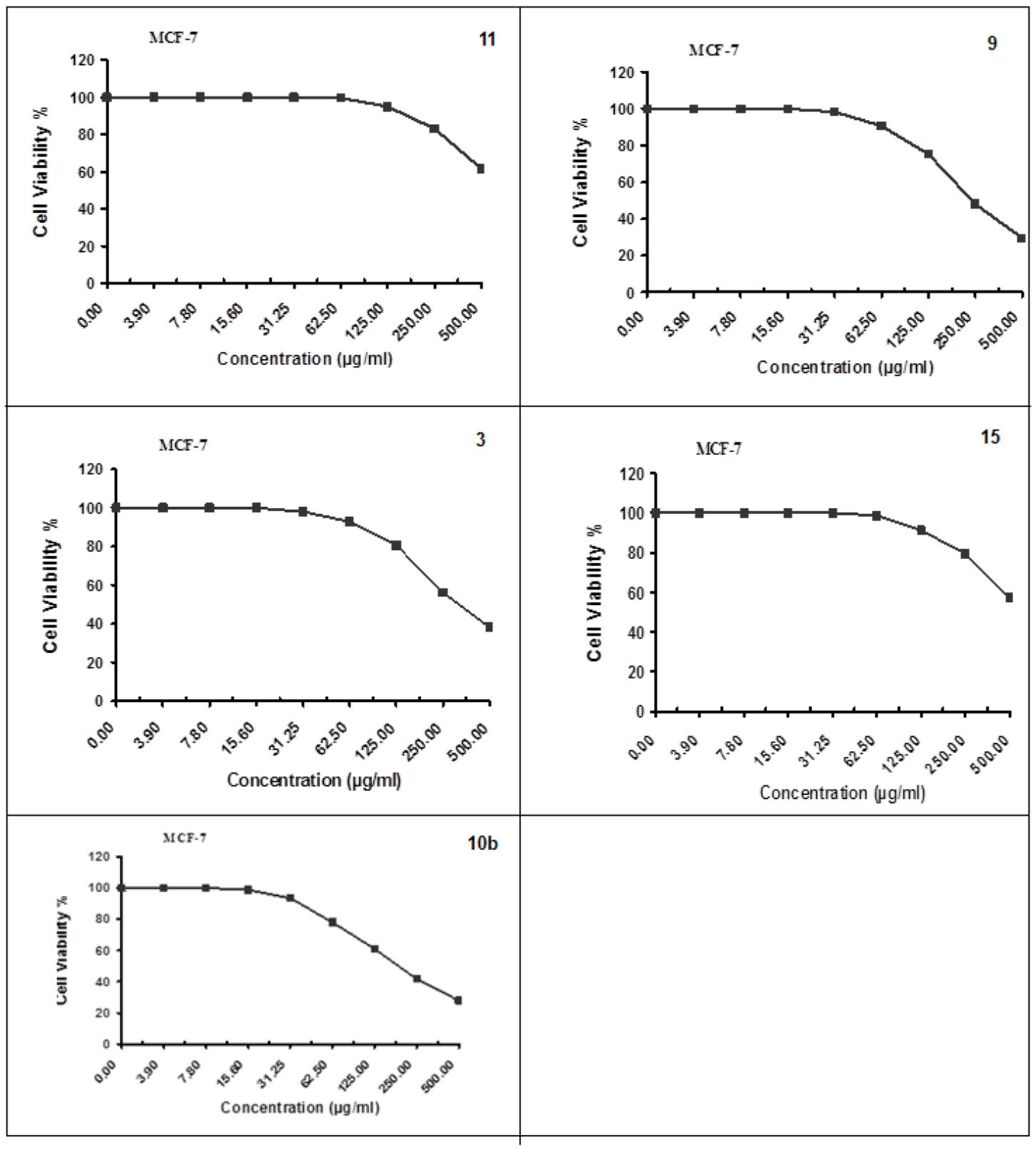




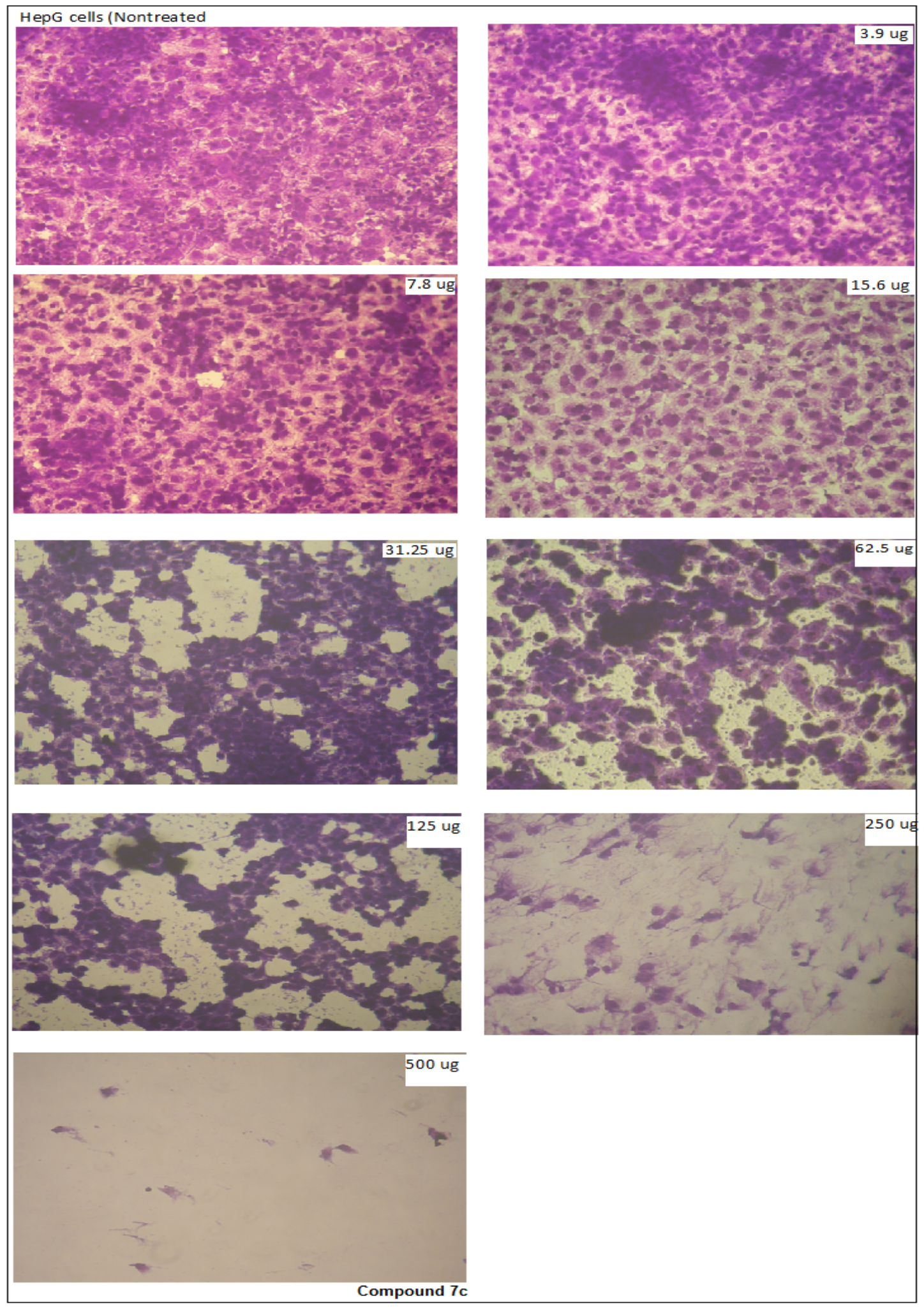

\section{Acknowledgements}

We would like to thank the Science \& Technology Development Fund in Egypt STDF Project ID: 22909 for funding this research proposal. 


\section{REFERENCES}

1. El-Rayes, S., Gomaa, M.S.,Abouelmagd, A., Fathalla, W., Ali, I.A.I.Synthesis and antiproliferative assay of triazolyl-2,2-dimethyl-3-phenylpropanoates as potential HDAC inhibitors RSC Advances 2019, 9(24), 13896.

2. S. M. El Rayes,A. Abo Elmagd,Gomaa M. S., Ibrahim A. I. Ali, Walid Fathalla, Faheem Hyder Pottoo,F. A. KhanConvenient synthesis and antiproliferative activity of methyl 2-[3-(3-phenyl-quinoxalin-2-ylsulfanyl)propanamido] alkanoates and N-Alkyl 3-((3-phenylquinoxalin-2-yl)sulfanyl) propanamides accepted in ACS Omega 2019 DOI 10.1021/acsomega.9b02320

3. N. Haider, T. Kabicher, J. Kaferbock, A.Plenk, Molecules, 2007, 12, 1900.

4. P. Gong, Y. B. Zhang, L. He, X. Zhai, Chin. Chem. Lett., 2008, 19, 29.

5. M. Asif Some Recent Approaches of Biologically Active Substituted Pyridazine and Phthalazine Drugs Current Medicinal Chemistry, 2012, 19, 2984-2991

6. P. Gong, X. Jing-Xion, Z. Yan-Fang, L. Juan, Molecules, 2006, 11, 574.

7. Huda R. M. Rashdan, Sobhi M. Gomha, Marwa S. El-Gendey, Maher A. ElHashash and Abdel Mohsen M. Soliman GREEN CHEMISTRY LETTERS AND REVIEWS 2018,11(3),264-274 https://doi.org/10.1080/17518253.2018.1474270

8. Mohammad Asif A BRIEF REVIEW ON PHARMACOLOGICAL EFFECT OF SOME PHTHALAZINE DERIVATIVES ON CARDIOVASCULAR AND KIDNEY FUNCTIONS Tech Journal of Pharmaceutical Sciences 2015, 4 (1), 17-26

9. Wagdy M. Eldehna, Hadia Almahli, Ghada H. Al-Ansary, Hazem A. Ghabbour, Mohamed H. Aly,Omnia E. Ismael, Abdullah Al-Dhfyan and Hatem A. AbdelAziz Synthesis and in vitro anti-proliferative activity of some novel isatins conjugated with quinazoline/phthalazine hydrazines against triple-negative breast cancer MDA-MB-231 cells as apoptosis-inducing agents JOURNAL OF ENZYME INHIBITION AND MEDICINAL CHEMISTRY, 2017, 32, NO. 1, 600613 http://dx.doi.org/10.1080/14756366.2017.1279155 
10. J. Y. Hwang, H.S. Choi, Y. D. Gong, Tetrahedron Lett. 2005, 46, 3107.

11. D. Vina, E. del Olmo, J.L. Lopez-Perez, A. San Feliciano, Pyrazolo[3,4,5-de] phthalazine. Syntheses of a practically unknown heterocyclic system, Tetrahedron 2009, 65,1574-1580.

12. Ibrahim. A. I. Ali, Walid Fathalla, S. M. El Rayes Convenient syntheses of methyl 2-[2-(3-acetyl-4-methyl-2-oxo-1,2-dihydroquinolin-1-yl)acetamido] alkanoates and their O-regioisomers ARKIVOC 2008 (xiii) 179-188

13. S. M. El Rayes Convenient synthesis of some methyl-N-[2-(3-oxo-6-p-tolyl2,3,4,5-tetrahydropyridazin-2-yl)-acetylamino]amino acid esters ARKIVOC 2008 (xvi) 243-254

14. S. M. El Rayes Convenient Synthesis and Antimicrobial Activity of Some Novel Amino Acid Coupled Triazoles Molecules 2010, 15, 6759-6772; doi:10.3390/molecules15106759

15. Walid Fathalla, S. M. El Rayes, Ibrahim A. I. Ali Convenient synthesis of 1substituted-4-methyl-5-oxo [1,2,4]triazolo[4,3-a]quinazolines ARKIVOC 2007 (xvi) $173-186$

16. K. Hofmann, T. A. Thompson, H. Yajima, E. T. Schwarts, H. J. Enouye, Chem. Soc. 1960, 82, 3715.

17. Elrayes. S. M, ; Ali. I.A. \& Fathallah. W; Convenient Synthesis of Some Novel Pyridazinone-Bearing Triazole Moieties, J. Heterocyclic Chem. 2019, 56, 51. : DOI: $10.1002 / 3369$.

18. A. B. Waleed, M. B. Alaa-Eldin, M. G. Magdy, M. A. Mohamed, M. A. Ali, Der Pharma Chemica 2014, 6(3), 89-102

19. Mosmann, T.; Rapid colorimetric assay for cellular growth and survival: application to proliferation and cytotoxicity assays. J. Immunol. Methods; 1983 65, 55-63.

20. Gomha, S.M.; Riyadh, S.M.; Mahmmoud, E.A. and Elaasser, M.M.; Synthesis and Anticancer Activities of Thiazoles, 1,3-Thiazines, and Thiazolidine Using 
Chitosan-Grafted-Poly(vinylpyridine) as Basic Catalyst. Heterocycles; 2015, 91(6):1227-1243.

21. M. A. Tantawy, M. S. Nafie, G. A. Elmegeed and I. A. I. Ali, Bioorg. Chem., 2017, 73, 128-146. 